\title{
Sobre ciertas joyas del siglo XVI y su relación con fuentes documentales y retratos
}

\author{
Natalia Horcajo Palomero *
}

Posiblemente una de las creaciones más imaginativas de la Historia del Arte, sean las joyas. Ellas por su pequeño tamaño podían ser llevadas de un sitio a otro, contribuyendo a difundir novedades estilísticas, y convertirse a la vez, en uno de los obsequios más apreciados para su destinatario, con independencia de su edad o sexo, aunque tradicionalmente fuese y siga siendo la mujer su mejor "consumidora".

Como cualquier otra manifestación artística, las joyas también tienen historia, una historia larga, que se remonta a los orígenes del hombre, ya que no es difícil encontrar joyas prehistóricas en las vitrinas de los Museos Arqueológicos, y que se puede continuar ahora mismo, al contemplar una pieza de Vasari en el escaparate de una buena joyería.

A lo largo de esta historia, esos pequeños objetos tan deseables han ido variando no sólo en los materiales que los conforman, sino también en su diseño y formas, de manera que puede hablarse con toda exactitud, de una "Joyería Gótica», o de una "Joyería Art Decó", que se insertan perfectamente en el período cronológico en que estos movimientos artísticos estaban en pleno apogeo.

De todas estas «joyerías", quizás la más original y creativa sea la del Renacimiento. En un momento de la vida de la Humanidad en la que las Artes cobraban un valor extraordinario y los artistas empezaban realmente a convertirse en protagonistas de sus propios destinos, las joyas se abren paso con un esplendor inusitado, contribuyendo a señalar la importancia y el prestigio de sus propietarios, que las llevaban orgullosos en sus retratos y han dejado constancia de ellas en sus escritos.

Son varias, pues, las fuentes a las que se debe acudir, si algún estudioso quiere aventurarse en ese mundo misterioso y mágico, porque las

* Dra. Historia del Arte. 
joyas también actuaban como amuletos y talismanes, que constituye la "Joyería Europea del Renacimiento", concretamente cuatro: Ejemplares conservados en Museos y colecciones privadas; diseños, dibujos y grabados, destinados a su ejecución, documentos de la época y la pintura de retratos.

En principio parece un estudio sencillo y poco complejo, pero al iniciarse empiezan a surgir las complicaciones, porque, aunque todas las fuentes citadas aportan abundante material, es prácticamente imposible su relación.

La lógica conduce a pensar, que si una persona importante, monarca, banquero... quisiera encargar una joya, lo primero que tendría que hacer sería contactar con un joyero y expresarle sus deseos, éste entonces procedería a mostrar a su cliente varios bocetos de diseños, propios 0 ajenos, de cómo podría ser esa joya, para que escogiese, y una vez celebrada esta consulta y firmado el contrato o bien apalabrado, el orfebre ejecutaría la pieza, según el modelo, que finalmente recibiría, previo pago de su importe, quien la había encargado. A continuación, si su propietario era un gran personaje, se haría retratar llevándola, si fuese él, el destinatario del encargo, o se la encontraría en el retrato de otra persona, en el caso de ser un regalo, y posiblemente en ambos casos, a su muerte aparecería inventariada entre sus bienes, o entre sus disposiciones testamentarias.

Así, efectivamente, son muchas las joyas del siglo xvi, conservadas, casi dos mil, y cerca de setecientos los diseños, dibujos y grabados, que han llegado hasta hoy, numerosos los documentos que sobre ellas guardan los archivos, y bastantes los retratos en los que las joyas se prodigan para realce del retratado, mas el gran problema surge cuando, se quiere establecer cualquier tipo de relación entre todos ellos, porque los puntos en común, son prácticamente inexistentes.

Hay joyas similares a las proyectadas en un diseño, pintadas en un retrato, o descritas en ciertos documentos, pero, salvo excepciones, sólo eso, similares, ya que no se conserva ningún ejemplar con su dibujo o grabado, su presencia en cualquier retrato y su constancia documental.

Las razones de este caos son difíciles de explicar, quizás se deban a que la mentalidad del hombre del Renacimiento no se guiaba por las mismas premisas que la actual, o lo que es más factible, que muchas, muchísimas joyas de aquel momento se deshicieron para volver a ser montadas, tal como afirman en numerosas ocasiones los documentos.

Aunque como se acaba de exponer, es imposible conciliar la totalidad de las fuentes de estudio, algunos datos proporcionados por ellas, per- 
miten encontrarse con planteamientos erróneos o con sorpresas muy agradables.

Existe un bellísimo collar, conservado en Alemania, en el Schatzkammer de Munich (fig. 1), que Steingräber afirma ${ }^{1}$ que pertenecía al Duque Alberto $V$ de Baviera, pues aparece en su Cámara de Joyas entre 1565 y 1579 , señalando más adelante, que según un inventario de 1637 , se trataba de un trabajo español, advirtiendo que posiblemente se trate del collar que Felipe II de España regaló a la nuera del Duque, Renata, con motivo del bautismo de su hijo en 1576.

Este collar, que pasó a llamarse de "La Orden de los Caballeros de San Jorge", tras su uso en las ceremonias de dicha Orden a partir del siglo XVIII, es de oro esmaltado con esmeraldas, rubíes, diamantes y perlas engastados, aunque las esmeraldas han sido sustituidas recientemente por imitaciones. Está formado por dieciséis eslabones, ochos piezas y ocho entrepiezas, y un pinjante. Las piezas están compuestas por roleos calados, engastadas en su centro por una esmeralda(?) o un rubí, cuadrados tablas, en monturas piramidales, flanqueados por dos barras cruzadas de diamantes, igualmente cuadrados tablas, siendo la pieza central diferente, algo más grande, engastada con un rubí cabujón oval, rodeado de diamantes triangulares punta naife. De esta pieza cuelga un pinjante, una esmeralda(?) hexagonal talla tabla en una montura formada por un cerco de oro labrado. Las entrepiezas, con una montura de roleos similar a la de las piezas, están engarzadas con una perla redonda, rodeada por cuatro diamantes cuadrados tablas ${ }^{2}$.

Por fortuna, el Archivo General de Simancas, conserva entre sus legajos un documento, que describe el collar regalado por Felipe II, que se expone a continuación:

«Memoria de la joya que se embio para el baptismo del hijo del Duque de Baviera.

La joya que su Magestad embia para la nuera del Duque de Baviera, es, un collar de oro y diamantes, esmaltado de blanco, colorado, verde y azul, que tiene diez y seis pieças engarçadas una con otra, de esta manera, una pieza principal que tiene una rosa de diez diamantes jaquelados, y otras ocho pieças que cada una dellas tiene una rosa con nueve diamantes, y otras siete pieças con cinco diamantes cada pieça, uno pequeño y quatro mayores.

Steingräber, E., Antique Jewellery: Its History in Europe from 800 to 1900. London, Thames \& Hudson, 1957, pág. 113.

2 Horcajo Palomero, N., Joyería Europea del siglo xvi. Estudio tipológico y temático. Madrid, Editorial de la Universidad Complutense, 1991-1992, Tomo II, págs. 879-880 


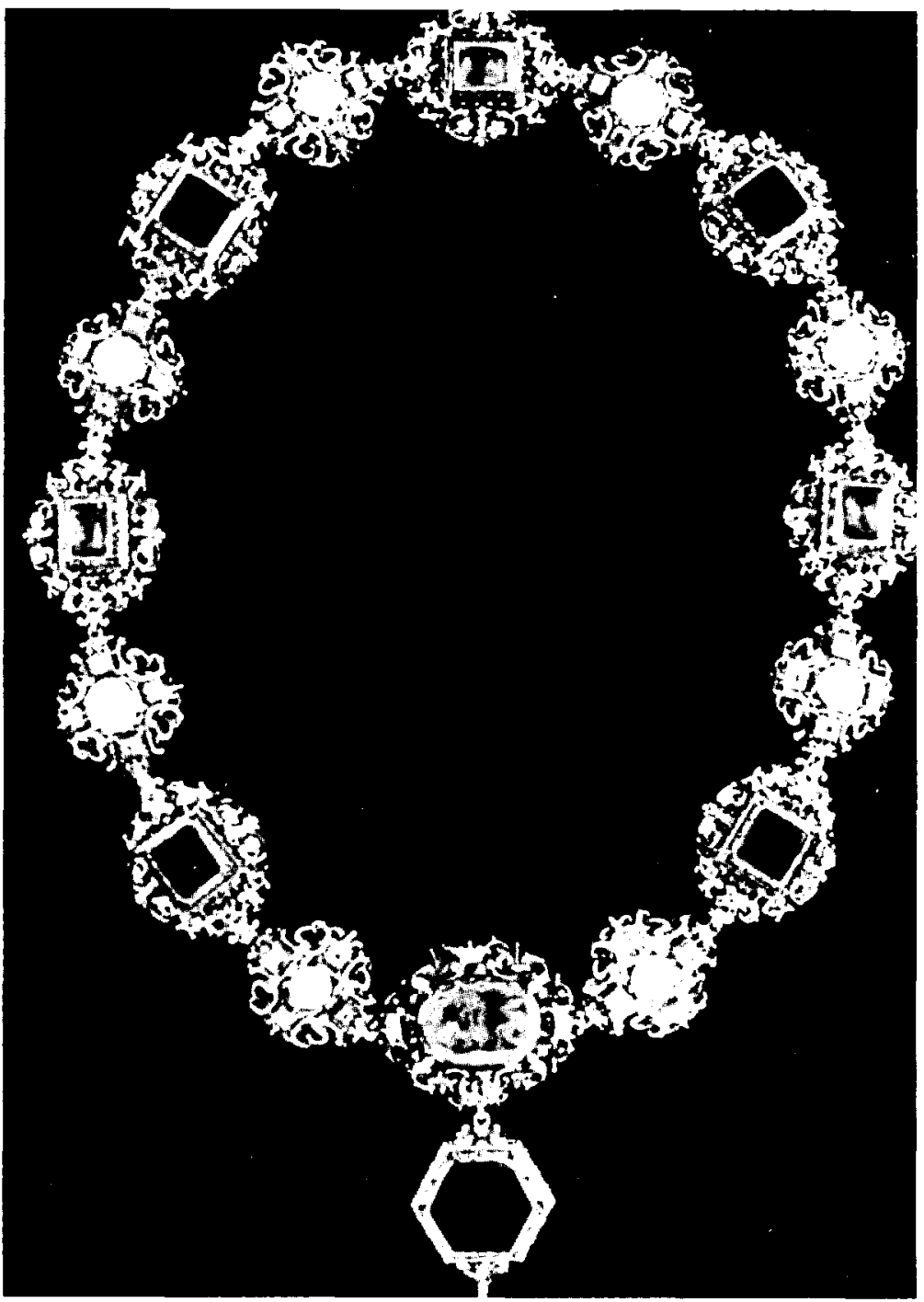

Fig. 1. Collar denominado de la "Orden de los Caballeros de San Jorge", pertenecientes al Duque Alberto $V$ de Baviera. Posible trabajo alemán de la segunda mitad del siglo xvi. Schatzkammer der Residenz, Munich. 
Estimando todo el dicho collar en quatro mill y quinientos ducados" (La tasa está tachada) ${ }^{3}$.

Pasando por alto el lío familiar del escribano o secretario real, que primero habla del «hijo" del Duque de Baviera, y luego de su nuera, Renata, destinataria final del regalo, inmediatamente se comprueba que el collar que conserva el Schatzkammer, no es el enviado por el monarca español, del que se desconoce el paradero, siendo posible que fuese refundido y convertido en otra joya, mientras que sus diamantes serian igualmente engastados en otras piezas. Esta vez, por lo tanto, no hay relación entre el documento y el collar, para el que se debe de buscar otra procedencia.

Más a veces, se tiene suerte, y es posible hacer ciertas identificaciones y poner en relación dos o más fuentes.

Hackenbroch en su obra "Renaissance Jewellery» ${ }^{4}$, ya señala alguna pieza de joyería conservada que puede ser reconocida en un retrato, sería el caso de un colgante relicario, conteniendo dos miniaturas y engastado con un camafeo oval con el busto de una negra, conocido como la "Joya Gresley", datado de la segunda mitad del siglo XVI, perteneciente a una colección privada, que aparece perfectamente identificable en el retrato de su propietaria, Catherine Walshinghan, de 1585, en la Birminghan Fine Arts Gallery, identificación que también se recoge en "Princely Magnificence ${ }^{5}$, donde además se apunta que las miniaturas pertenecen, por comparación con el retrato citado, a Catherine Walshingham y a su marido, Sir Thomas Gresley.

Este es sin duda un caso curioso de identificación, pero no lo es menos el que pone en relación unas joyas propiedad de la cuarta esposa del Rey Felipe II de España, Ana de Austria, reproducidas en tres de sus retratos, y el documento que narra la ceremonia de sus Desposorios, por poderes, en Praga, conservado en la Biblioteca Nacional de Madrid ${ }^{6}$.

Las joyas son, un colgante figura-heráldico, en forma de un águila bicéfala, coronada, con las alas explayadas, divisa de los Habsburgo, familia a la que la nueva Reina pertenecía doblemente por parte de padre,

\footnotetext{
3 "Archivo General de Simancas", Estado, Legajo 677, Folio 49. “Memoria de la joya que se embio para el baptismo del hijo del Duque de Baviera".

4 Hackenbroch, Y., Renaissance Jewellery. London, Sotheby Parke Bernet Publications by Philip Wilson Publishers Ltd, 1979, pág. 296, lám. 792 y 793 a y b.

5 Somers Cocks, A.G., et alii, Princely Magnificence. Court Jewels of the Renaissance, 15001630. London, Drebrett's Peerage Ltd. 1980, pág. 62, lám. 46.

6 Horcajo Palomero, N., Op. cit., Tomo IV, págs. 250-251.
} 


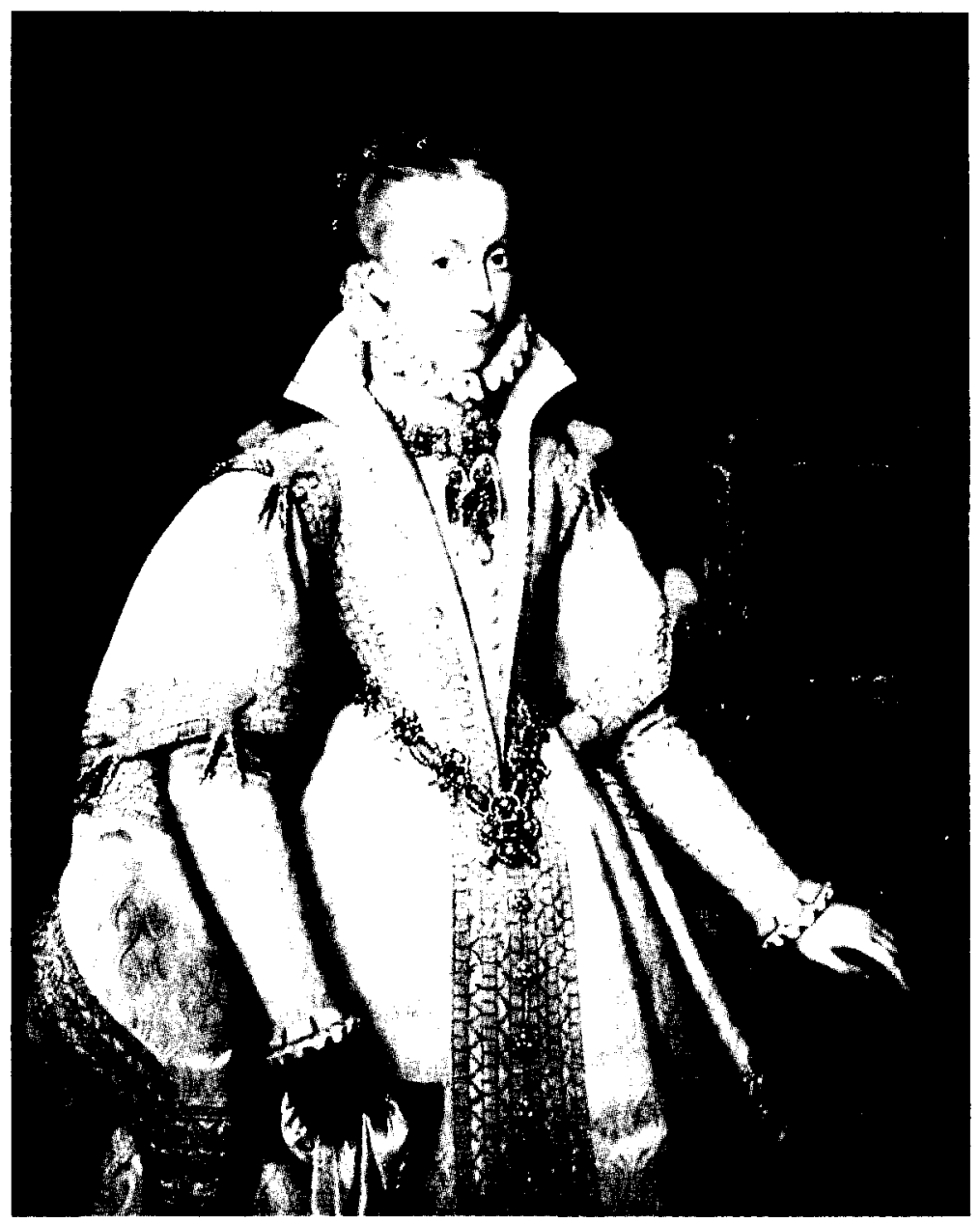

Fig. 2. Retrato de Ana de Austria por Bartolomé González, (copia de Antonio Moro). Museo del Prado, Madrid.

Maximiliano II, y madre, María de Austria, hermana de Felipe, y una cintura o cinturón, con todas las piezas iguales, incluida la broncha, algo mayor, formadas por monturas de oro con piedras tablas y perlas engastadas, entrelazadas con cordones de San Francisco, posible alusión de la pertenencia de Ana a la Orden del Cordón de San Francisco, instituida por Ana de Bretaña en 1498, con miembros exclusivamente femeninos. 
El colgante y la cintura, aparecen en dos retratos, obras de Antonio Moro y de Bartolomé González (figs. 2, 3 y 4), en el Kunsthistorisches Museum de Viena y en el Museo del Prado de Madrid, respectivamente. La cintura sola, es vuelta a identificar en otro retrato, por Alfonso Sánchez Coello, conservado también en el Kunsthistorisches.

En cuanto al documento, es notable constatar como describe estas joyas, haciendo posible su identificación, acontecimiento muchas veces buscado y pocas conseguido.

Ante la disyuntiva de exponer la transcripción completa del documento, o sólo el fragmento que describe las joyas mencionadas, se ha optado por lo primero, debido a lo interesante y curioso de la narración:

«Relación de lo subcedido en el desposorio del Serenisimo Rey de España, nuestro Señor, con cuyo poder se desposo el Serenisimo Principe Carlos, archiduque de Austria, con la Serenisima ynfanta Ana enpraga, a los quatro dias del mes de mayo, dia de la açension de nto Redentor y Salvador Jesucristo, de 1570 alas tres horas dela tarde, despues de comer, que no se hallo en el la Serenisima princesa Doña Ysavel, pores tar yndispuesta de sarampion. Salio de su camara la Magestad del emperador, con una ropa corta a la francesa, de terciopelo negro muy bien guarneçida delo mesmo, con muchos botones de oro y unagorra adereçada con plumas, blancas y amarillas, y calças de terciopelo carmesí, contafetanes de tela de oro carmesi de labor y jubon de la dicha tela de las calças, muy rico y coleto de cuero blanco adobado de ambax con botones de oro con la dicha ambax, y salieron con su Magestad Cesarea el Serenisimo Archiduque Carlos, con una ropa de rasso negro muy bien guarneçida de terciopelo, con muchos botones de oro, con tafetanes de tela de oro encarnada de labor rica, con el jubon lo mismo, con un coleto de cuero adornado de ambax con botones de oro con la dicha ambax.

Su Magestad de la emperatriz, salio de su camara llevando trassi a la serenisima Princesa ana y llevava vestida una basquiña ricade tela de plata. Rosa bordada todacuajada de unos bastones y hojas de oro y Plata guarneçida contiras de raso blanco bordados asi mesmo de los dichos bastones y hojas del dicho oro y plata, con las dichas ataduras, con un Ropón de terciopelo negro con mucha spiga, abierto con puntas de cristal guarnezidas de oro blanco, con un jubon de rasoblanco picado y guarneçido el peso contrenças de horo hilado, tocada con muchas piedras y perlas gruesas y dela toca colgada una cruz de diamantes, grande, nueva mente hecha de mucho valor, contres grandes perlas por pinjantes de hechura de peras. Llevava su magestad consigo noventay seis damas con las de fuera, todas vestidas de telay de sedas bordadas de oro y Plata, con muchas joyas y botones, todas sus damas con mangas de Punta que su Magestad les hizo en medio(?) de las sayas. Su alteza de la ynfanta Ana salio con una saya de raso carmesi encarnado, con gran falda con cuerpo alto y mangas de punta bordadas, todas quajadas de franjuelas deoro y Plata, de una obra muy graciosa, de unas hojas al giutesco, con unas ataduras apartes de cartones de oro y Plata muy bien hecha, sembrado aparte por la dicha saya mucha cantidad de botones de oro. En 


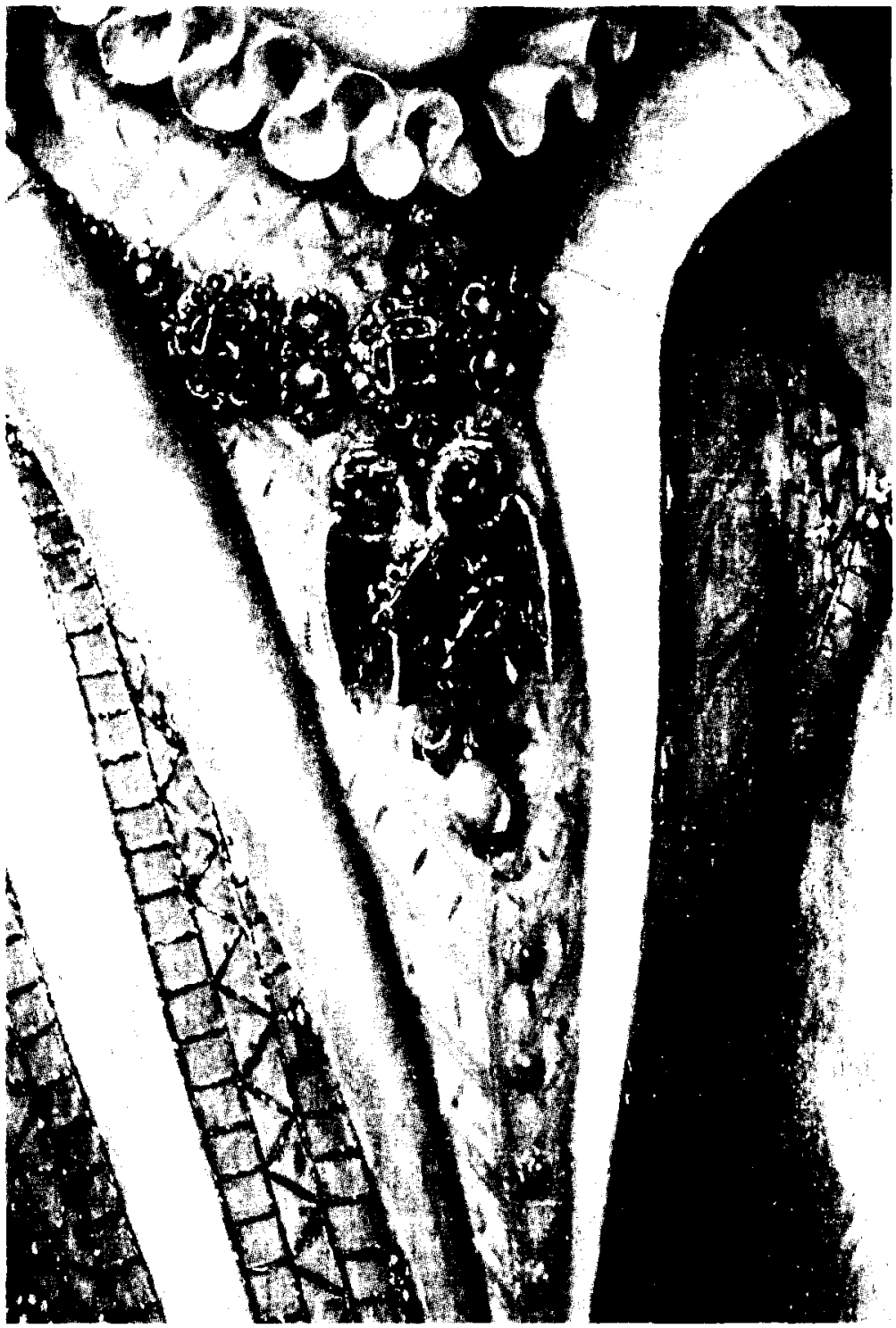

Fig. 3. Detalle del colgante figura heráldico, en forma de águila bicéfala, coronada, con las alas explayadas, divisa de los Habsburgo. 
el cuerpo y delanteras de unos diamantes puntas grandes y rubis berruecos que hacian muy linda vista, aforradas las mangas en tela de plata frisada de unas aguilas Ymperiales muy ricas. En la cabeza llevava un tocado muy gracioso de sus mesmos cabellos, con unas ataduras de çintas encarnadas y oro, con muchas perlas y ruvis y diamantes y pendella un joyel muy grande e rico que tiene una grande esmeralda abaxo en el pie del, y encima un muy hermoso ruvi grande y en los pilaresque tiene a los lados quatro diamantes y dos ruvis grandes, con una perla ençima de cada pilar, gruesa redonda, y por pinjante una perla grande pera y en medio del joyel, un buey con una doncella con flores en la mano, y del cuello colgado una muy hermosa sarta de perlas gruesas redondas de mucho valor, y en los pechos un JOYEL QUEES UNA AGUILA GRANDE YNPERIAL CON DOS CABEZAS, CON UN DIAMANTE METIDO ENLOS PECHOS Y CUERPO GRANDE TABLA MUY HERMOSO, Y EN LOS PICOS TENIAN LA DICHA AGUILA DOS RUVIS GRANDES ENGRANPADOS MUY RICOS Y POR PINJANTES UNA PERLA MUY GRANDE A MANERA DE HOGAZA, CON UNA CINTA DE UNAS PIEZAS A MANERA DE LAZADAS HECHAS DE CORDON DE SAN FRANCISCO, CON UN DIAMANTE GRANDE TABLA EN CADA UNA, CON CUATRO PERLAS GRUESAS REDONDAS QUE LA TIENEN EN MEDIO, y llevava la falda doña maria decardona, camarera mayor de su magestad de la enperatriz, hasta que se canso, que la tomo despues en su lugar Doña Margarita Laso de la (ilegible), aposento de su Magestad de la emperatriz para yr a la yglesia, y fueron su Alteza del Archiduque delante y sus Magestades del enperador y la enperatriz juntos, y su Ateza de la princesa detras dellos, hasta que llegaron por un pasadizo a la iglesia mayor desta cibdad, donde avia hecho un cadahalso que subia çinco gradas, y mas adelante en el coro de la yglesia, delante el altar mayor, havia otro de tres gradas, encima del qual avia un cielo de brocado con frisadura dorada, donde arrimado el altar el arzobispo desta cibdad vestido de Pontifical muy ricamente. El hornamento rico de perlas de la emperatriz, acompañado del ocho obispos, todo asi mesmo de pontifical con sus mitras y a la mano derecha del altar estava un dosel muy grande de brocado rico frisado con seda morada y blanca, y con un sitial grande del brocado rico de tres altos carmesi, donde estavan primero el enperador y luego su Magestad de la enperatriz, y tras ellos su Alteza del Archiduque Carlos y luego su Alteza de la Princesa ana, alli junto la serenisima ynfanta doña Margarita su hermana, vestida de tela de plata fresada, con su aya que la tenia en brazos y mas Adelante, muy apartado el Duque de mequelburque, vestido a la Alemana, de terciopelo negro muy bordado de horo de la otra parte de la mano izquierda del arzobispo, un banco con antepecho cubierto de terciopelo carmesi, donde estaba el nuncio, el embaxador de España y luego el de Polonia y Venecia y Saboya, venian(?) por su Horden, y alli en el dicho coro, las damas todas y alrededor muchos cadahalsos con mucha gente. $Y$ el dicho arçobyspo empezo ahazer una platica declarando el acto que se queria hazer y mando leer aun capellan el brevey dispensacion que su Santidad dio para q este matrimonio que Dios nto señor dexegozar apadres e hijos muy largos años, como a todos sus criados y vasallos deseamos y demas menester huviese hefecto. Leydo que fue esto, un vizcançiller de su Alteza el Archiduque presento el Arçobispo un poder que tenia de su magestad Catolica paraq desposarse porel con 


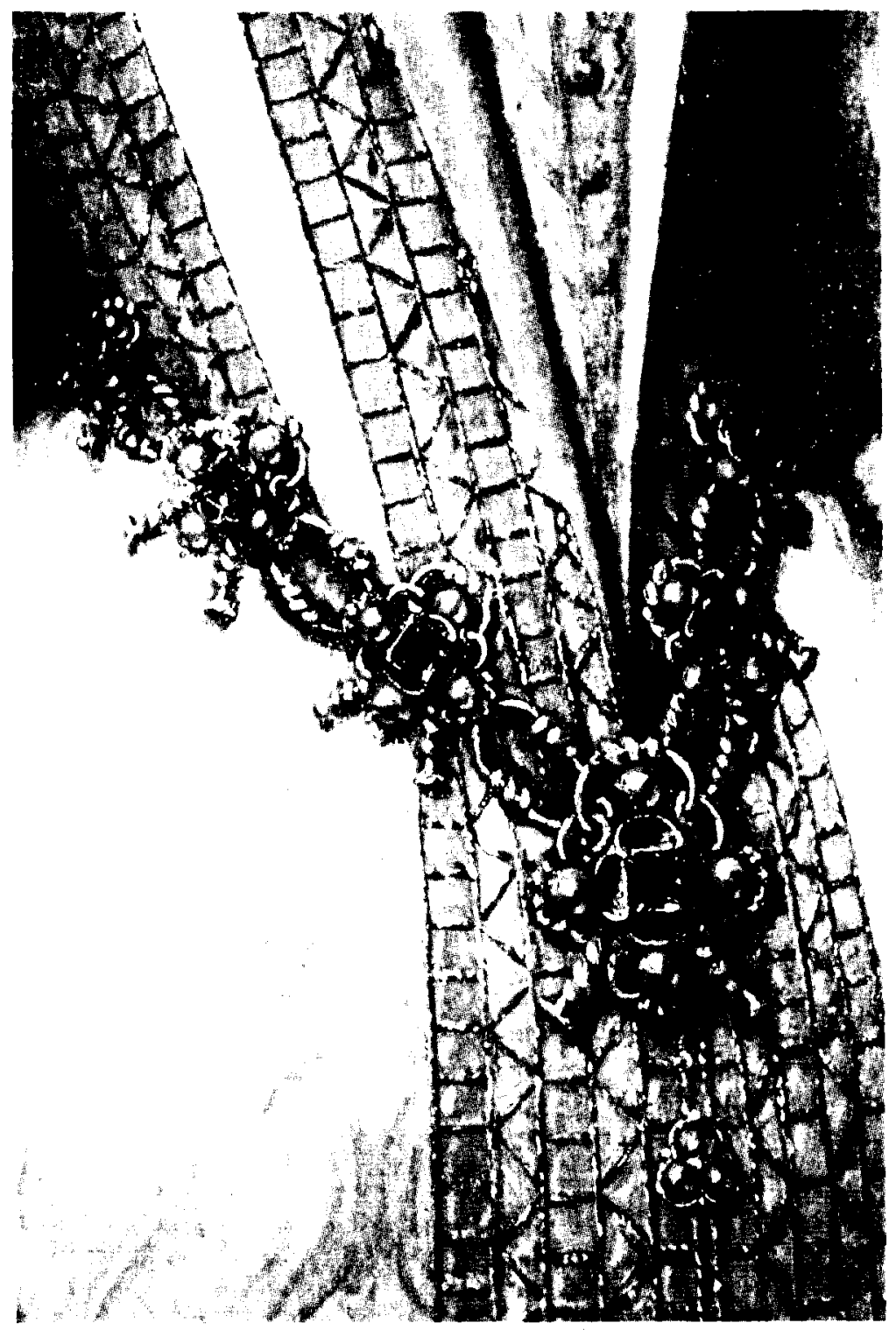

Fig. 4. Detalle de la cintura o cinturón, con los cordones de San Francisco. 
doña(?) a la cual el dho arçobispo dio al dicho capellan y leleyo como lo demas, atodo esto su Magestad y Altezas estuvieron enpie, y como fue acabado salieron de su sitial todos, y subieron al cadahalso, donde el dicho arçobispo estaba, y su magestad Cesarea el emperador con su Alteza del archiduque a la mano derecha del dicho arçobispo, se llegaron, llevando su magestad a su alteza a su mano derecha, de la otra parte estaba su magestad Cesarea de la enperatriz, con su alteza de la princesa Ana a mano derecha. El arçobispo interrogo como escostumbre a su alteza del archiduque y despues a su alteza de la princesa, la cual pidio liçencia a sus padres para responder y se la dieron. Este ynterrogar fue tres vezes, luego el dicho Arçobispo dio a su alteza del archiduque, un anillo riquisimo que el embaxador de su Magestad Catolica mando hazer de nuevo con un diamante grande tabla y en los brazos a cada parte del diamante, dos ruvis grandes pelongados tablas, y ocho diamantes alrededor, a manera que todo hera joya muy graciosa y rica, y su alteza de la princesa dio otro muy rico anillo, de un diamante muy grande tabla, muy hermoso, y diole al Archiduque, y el archiduque dio a su Alteza el otro que tenia, luego el dicho arçobispo les hizo dar de las manos y dixo las palabras sacramentales acostumbradas Rebolviendoles la estola a las manos, y hecholes la bendicion e su magestad catolica fue luego a sus padres a les besar las manos, y no se las dieron, sino la abraçaron. Luego el Embaxador de su magestad Catolica, sentado en su silla gotoso, se humillo ante su magestad de la Reina y le beso la mano, como criado y basallo y bolvio a hablar con su Magestad Cesarea del emperador y le quiso besar la mano y su mag no se la dio y le dio un abrazo y lo mismo hizo a su mag de la enperatriz, luego llego a su magestad catolica Luis Vanegas de Figueroa y le beso la mano asi mismo, como criado y vasallo, y fue a su mag Cesarea y le quiso asi mismo besar la mano y no se la dio, y le dio otro abrazoy le pidio liçencia para dar a su Magestad Catolica otra carta del Rey, y se la dio, y asi mismo hizo a su Magestad de la enperatriz, que le dio la dicha licençia y bolvio a su Magestad de la Reina y le dio la carta y torno a besarla la mano, antes que se la diese,y le hablo y despues de dada se la torno a besar otra vez, luego se fueron a sentar en su sitial como estaban, y se canto un tedeum laudamos y acabado, empezaron visperas solemnes de pontifical, y acabadas que fueron, se bolvieron alaposento del emperador, de la manera que fueron, y se asentaron a cenar desta manera, debaxo de un dosel de brocado rico, carmesi frisado, el emperador y su magestad de la emperatriz, a su mano derecha a la cabezeia de la mesa, luego su alteza del Archiduque, tras el la Reina Catolica, luego, apartados mas abaxo, el enbaxador y el nuncio del Papa y luego el enbaxador de Polonia y Venecia, de la otra parte a la mano izquierda, apartado de su Magestad Cesarea el enbaxador de España sin bonete, y tras el duque de Mequelburque, donde cenaron con mucha musica de menestriles y cantores, acabada la çena, de allí a una ora, se fueron a una muy grande sala, ricamente adereçada y huvo muy principal sarao, dondeseavia muchas damas y cavalleros, danço primero su alteza del Archiduque con la Reina una alemana, y el emp. con la emperatriz, y así acabado el dicho sarao, se bolvieron a sus aposentos, que Plega a Nto Señor guarde a su Magestad y altezas tantos años, con 
mucho acrescentamiento de sus Reinos y contentamiento, goçandose juntos como la cristiandad amenester" ${ }^{7}$.

Lástima que no se tenga ninguna noticia sobre el paradero actual del hermoso colgante que la nueva Reina de España llevaba prendido del pelo, que por la descripción que de él realiza el documento, debería ser un colgante renacentista figurado con el tema de Europa raptada por el toro (Júpiter), posiblemente de factura alemana y de la segunda mitad del siglo XVI, ni de las sortijas de esponsales, en especial de la de Ana, pero en el mismo documento se señala que el embajador la había mandado hacer de nuevo, por lo que es posible que más tarde volviese a correr la misma suerte, cambiando de forma y de mano. Sí resulta interesante también, tener en cuenta la cruz que lucía María de Austria, madre de Ana, en la ceremonia, y aunque el documento no la describe con exactitud tal vez sea la que lleva en el retrato pintado por Antonio Moro en 1551, en el Museo del Prado de Madrid, y en otro retrato, por el mismo pintor, en el Museo Royaux de Bruselas.

En el documento se describe una cruz de diamantes con tres perlas peras pinjantes, y en las pinturas se puede comprobar que la Emperatriz lleva una cruz así, sin duda de gran valor por el tamaño de los diamantes, $y$ es curioso observar como lleva un guante puesto y el otro quitado, como ocurre en los retratos de Ana por González, en el Prado y por Moro en el Kunsthistorisches.

De todas formas, y a pesar de las dificultades, resulta agradable cuando se trabaja sobre una materia, en este caso, la joyería europea del siglo xvi, realizar hallazgos, aunque sean escasos y perviva siempre el deseo de poder alcanzar logros mayores que permitan conocer un poco más ese mundo tan complejo e interesante que constituyen las joyas.

' "Biblioteca Nacional de Madrid", Manuscrito 1750, Vol. II, Folios 126-127. "Sucesos Políticos del Reinado de Felipe II y otros". 